\title{
High-Voltage Pulse-Assisted Electrochemical Machining
}

\author{
Haruki Obara ${ }^{*}$, Masato Isogai ${ }^{*}$, Takeshi Goda ${ }^{*}$, Tohru Sasaki ${ }^{*}$ and Yusuke Ikemoto ${ }^{*}$
}

(Received September 11, 2011)

*Department of mechanical and intellectual systems eng., Toyama Univ., Gofuku 3190, Toyama City, Japan

\begin{abstract}
In this paper, a new method of electrochemical machining (ECM), where high-voltage pulses are intermittently supplied to electrodes during low-voltage pulsed ECM, is presented. The properties of this method are compared with those of a conventional low-voltage pulsed ECM method using a $0.3 \mathrm{~mm} \phi$ electrode. We found that this method enables us to machine a workpiece using ECM conditions, that are difficult to use in the conventional ECM method, such as low electrolyte concentration and low pulse duty ratio. This method also enables us to machine a workpiece without strong flushing. The machining speed of this method is increased almost 3-6 times that of the conventional ECM method. A small side gap width comparable to the gap width by EDM is achieved using a low-density $\mathrm{NaNO}_{3}$ electrolyte.
\end{abstract}

Key words: ECM, high-voltage pulse

\section{INTRODUCTION}

Electrochemical machining is suitable for the mass production of parts, because tool electrodes do not wear during the machining. However, this method has some disadvantages. The first disadvantage is that the side gap width generated by ECM is on the sub-mm order and it is difficult to machine accurate structures. The second disadvantage is that the ECM requires the high-pressure flushing of the electrolyte. For the first disadvantage, Shuster et al. ${ }^{1)}$ presented a method using an ultrashort current pulse of 50ns or less. This method makes it possible to machine micro structures. However, this method is not useful for machining with macro or more larger electrodes. For the second disadvantage, Chikamori and $\mathrm{Ito}^{2)}$ reported that machining without flushing is possible by using a pulsed-current for ECM. However, the applicable ECM conditions for this method are restricted in a narrow range; thus, it is desirable to develop a method that is capable of using wide-range ECM conditions. Sakai et al. ${ }^{3)}$ used ECM for the finishing of surface products by electrical discharge machining (EDM), using a high-current pulse and the jump of a tool electrode. High-pressure flushing is not required. However, the effect of the method on sinking ECM is not clear. The effects of ECM conditions were well studied by De Silva et al. ${ }^{4), 5)}$. In this report, in order to improve the accuracy of ECM, we tried a new method of ECM, where high-voltage pulses are intermittently supplied between electrodes during low voltage pulsed ECM. The properties of this method are compared with those of a conventional low-voltage ECM in the case of a small electrode.

\section{EXPERIMENTAL METHOD}

Fig.1 shows a pulse image of the new ECM method, named high-voltage pulse-assisted electrochemical machining (HVPA-ECM). High-voltage pulses are intermittently supplied to the gap between the tool and the workpiece, together with a low-voltage pulse train. A couple of SUS304 stainless steel plates are set face to face in contact and their seam is machined at a depth of $0.5 \mathrm{~mm}$ using a $0.3 \mathrm{~mm}$-diameter tungsten electrode with $\mathrm{NaNO}_{3}$ electrolytes. The plates are separated after the ECM, and the cross-sectional shape of the machined

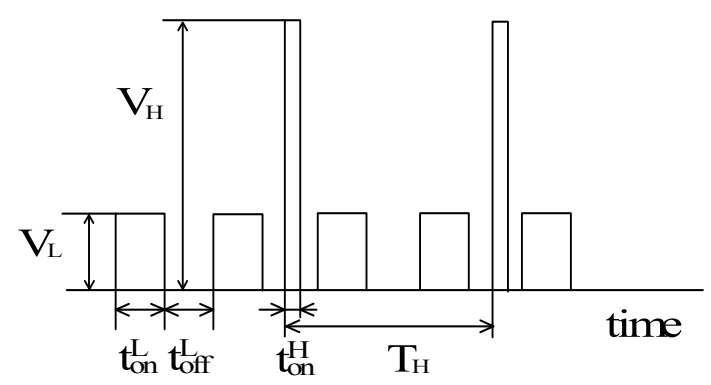

Fig.1 Pulse image of electrochemical machining combined with high voltage pulse 
hole is observed. The accuracy of the ECMed hole is estimated using the side gap width. The symbols in Fig.1 are used in the following.

\section{PROPERTIES OF CONVENTIONAL ECM}

\subsection{Electrolyte Flushing}

For the comparison of the HVPA-ECM and the conventional ECM, the properties of the conventional ECM are examined. Typically, ECM requires the high-speed flushing of the electrolyte on the few $\mathrm{m} / \mathrm{s}$ order. SUS plates are machined with a $0.3 \mathrm{~mm} \phi$

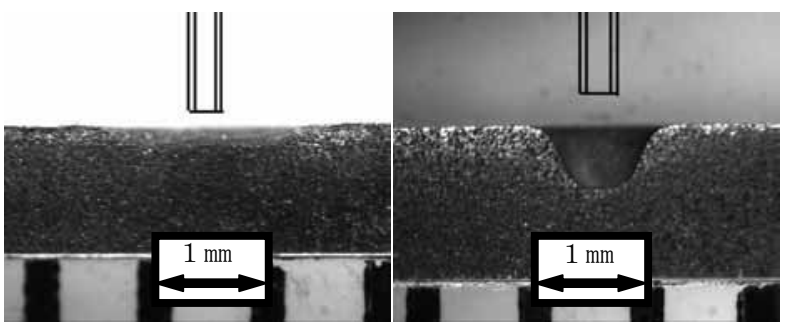

$0.1 \mathrm{MPa}(0.27 \mathrm{~m} / \mathrm{s})$

Fig.2 Influence of flushing pressure $\left(\mathrm{NaNO}_{3}: 5 \%, \mathrm{t}_{\text {on }}{ }^{\mathrm{L}} / \mathrm{t}_{\text {off }}{ }^{\mathrm{L}}=1 / 1 \mu \mathrm{s}, \mathrm{V}_{\mathrm{L}}=15 \mathrm{~V}\right)$

tungsten pipe electrode having an inner diameter of $0.1 \mathrm{~mm}$, by low-voltage pulsed ECM. Fig. 2 shows the cross-sectional shapes of holes machined at two flushing pressures from the pipe electrode. It was difficult to machine a hole with low-pressure flushing. Chikamori et al. ${ }^{2)}$ reported that the ECM in a stagnant electrolyte is possible by using a pulsed current. However, the workpiece is $\mathrm{S} 45 \mathrm{C}$ steel, the $\mathrm{NaNO}_{3}$ concentration is $30 \%$, and workable ECM conditions are restricted at the pulse width area of approximately $1 \mathrm{~ms}$ and the pulse period of $3 \mathrm{~ms}$. The ECM conditions shown in Fig.2 are far different from them. Hence, it was difficult to machine a hole without strong flushing. The following results in the case of low-voltage pulsed ECM are obtained using a pipe electrode and a flushing pressure of $0.8 \mathrm{Mpa}$.

\subsection{Effect of on/off duration of current pulse}

Fig. 3 shows the cross-sectional shapes of holes machined at maximum speeds, using the following ECM conditions; $5 \% \mathrm{NaNO}_{3}$, supply voltage of $15 \mathrm{~V}$ and pulse duration $t_{o n}{ }^{L}$ values of 1,10 , and $100 \mu \mathrm{s}$. The pulse interval is set so that $t_{o n}{ }^{L} / t_{\text {off }}{ }^{L}$ becomes $1 / 1$,

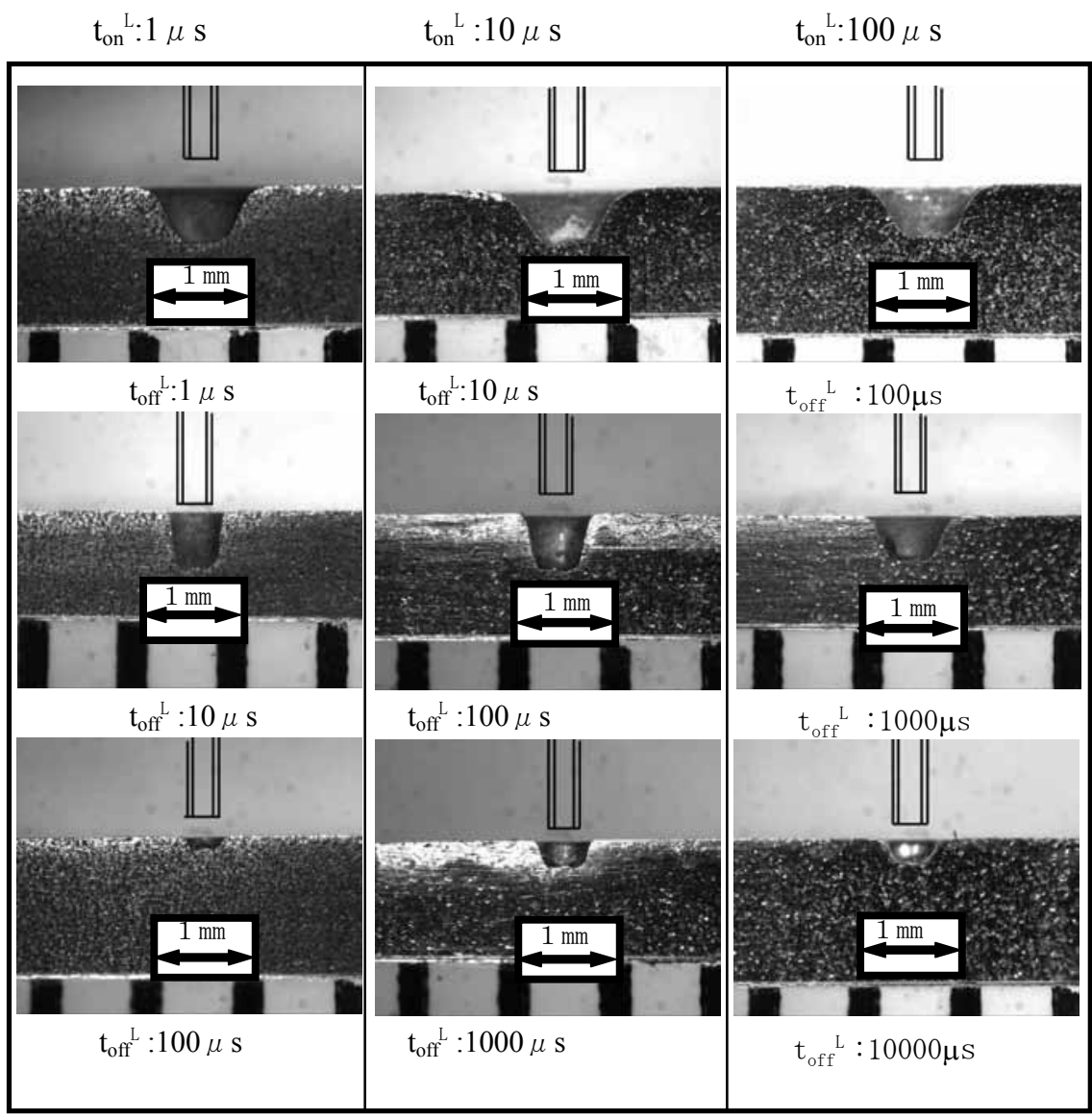

Fig. 3 Influence of $t_{\text {on }}{ }^{\mathrm{L}}$ and $\mathrm{t}_{\text {off }}{ }^{\mathrm{L}}$ on shape of hole machined by conventional pulsed ECM

$\left(\mathrm{NaNO}_{3}: 5 \%, \mathrm{~V}_{\mathrm{L}}=15 \mathrm{~V}\right)$ 
1/10, and 1/100. Fig.4 shows the machining speeds and side gap widths measured at a half-depth of the hole. The tool electrode is fed into the workpiece with a command feed rate. The command feed rate is adjusted so that the tool electrode and the workpiece do not discharge or contact. The machining speed and the side gap width decrease with the pulse interval. The short pulse duration causes the slow machining speed and the small side gap width. The machining at the depth of $0.5 \mathrm{~mm}$ is not completed at the point on dotted lines in Fig.4. An execively long pulse interval makes the machining impossible.

\subsection{Influence of $\mathrm{NaNO}_{3}$ concentration}

Fig. 5 shows the cross-sectional shape of the hole in the case of a $30 \% \mathrm{NaNO}_{3}$ electrolyte. The supply voltage is $15 \mathrm{~V}, t_{\text {on }}{ }^{L}$ is $10 \mu \mathrm{s}$, and $t_{\text {off }}{ }^{L}$ values are 10 , 100, and $1000 \mu$ s. Fig. 6 shows the machining speeds

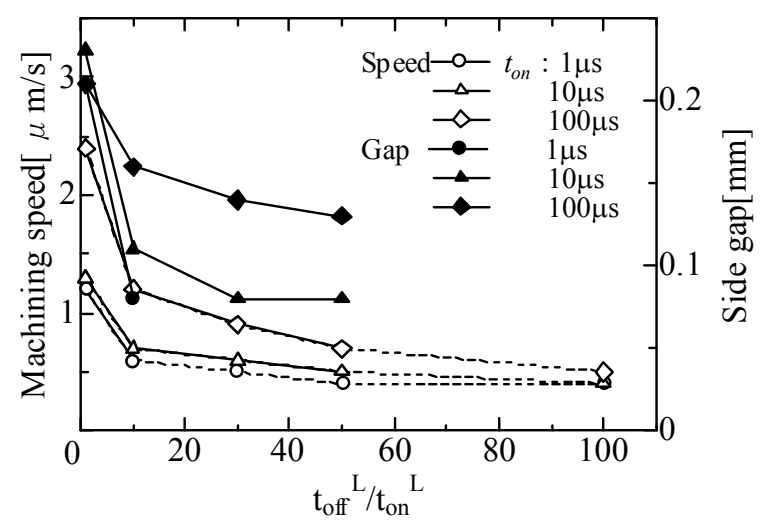

Fig.4 Machining speed and side gap width $\left(\mathrm{NaNO}_{3}: 5 \%, \mathrm{~V}_{\mathrm{L}}=15 \mathrm{~V}\right)$
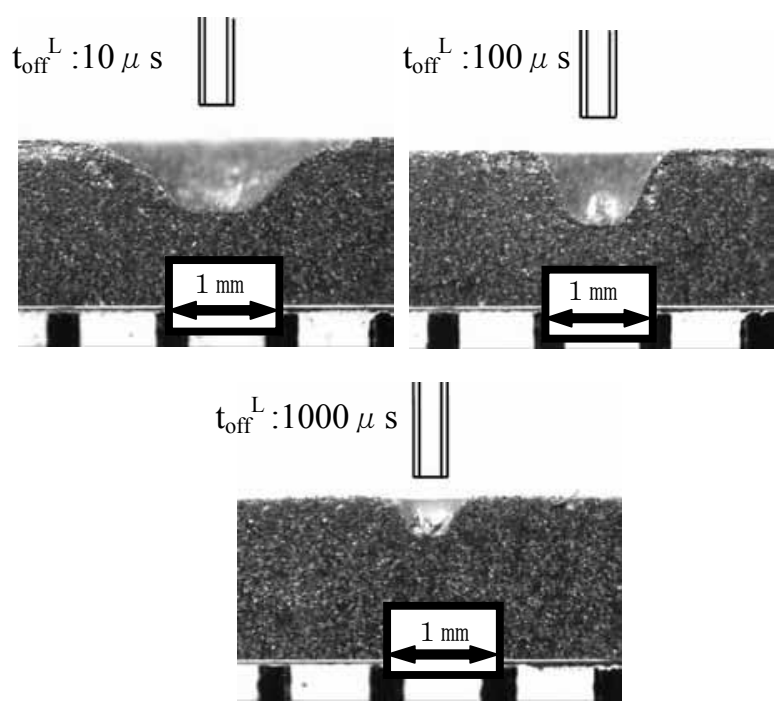

Fig. 5 Shape of hole machined by $30 \% \mathrm{NaNO}_{3}$

$$
\left(\mathrm{Vs}=15 \mathrm{~V}, \mathrm{t}_{\mathrm{on}}{ }^{\mathrm{L}}=10 \mu \mathrm{s}\right)
$$

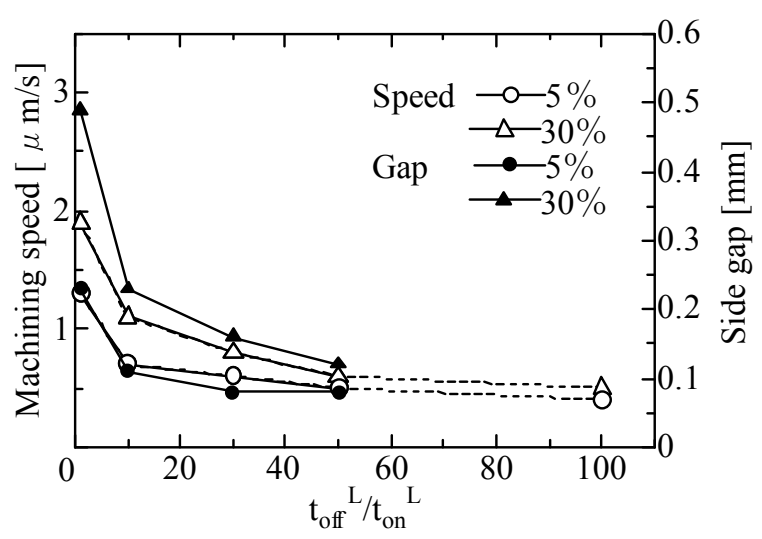

Fig.6 Machining speed and side gap width $\left(\mathrm{NaNO}_{3}: 5 \%, 30 \%, \mathrm{~V}_{\mathrm{L}}=15 \mathrm{~V}, \mathrm{t}_{\mathrm{on}}{ }^{\mathrm{L}}=10 \mu \mathrm{s}\right)$

and side gap widths compared with the results obtained in the case of a $5 \% \mathrm{NaNO}_{3}$ electrolyte.This high-density electrolyte results in a high machining speed, but a large side gap width, which is not desirable for accurate machining.

\subsection{Effect of supply voltage}

Fig. 7 shows the cross-sectional shapes of the holes machined at supply voltages of 5,10 , and $15 \mathrm{~V}$, using the $5 \% \mathrm{NaNO}_{3}$ electrolyte. The low supply voltage may cause the formation of small side gaps. However, the excessively low voltage makes machining impossible.

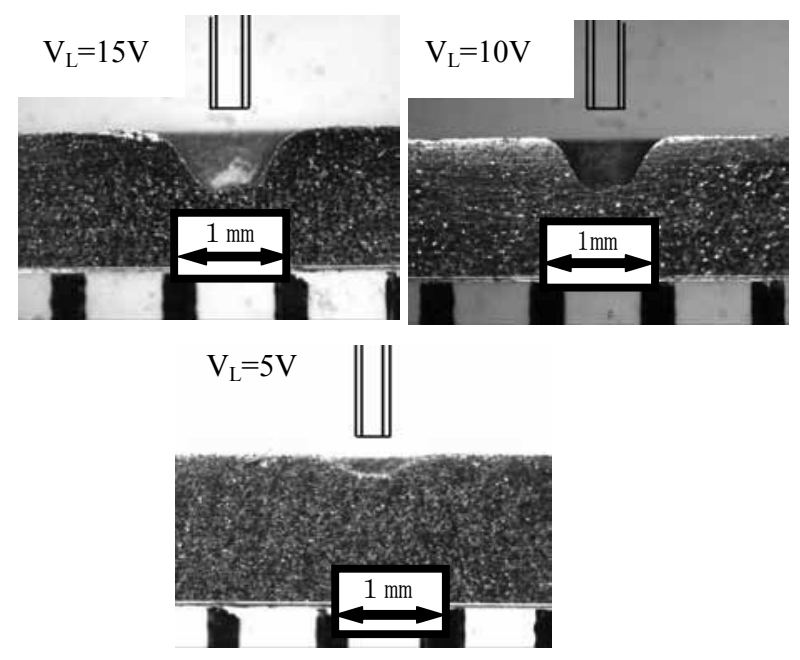

Fig.7 Influence of $\mathrm{V}_{\mathrm{L}}$ on shape of machined hole $\left(\mathrm{NaNO}_{3}: 5 \%, \mathrm{t}_{\text {on }}{ }^{\mathrm{L}} / \mathrm{t}_{\text {off }} \mathrm{L}=10 / 10 \mu \mathrm{s}\right)$

\section{HIGH-VOLTAGE PULSE-ASSISTED ECM}

\subsection{Electrolyte Flushing}

The conventional ECM requires high-speed flushing in the gap. However, it is difficult to form 
holes in a small electrode for flushing. Also, the flushing from the side of the electrode may form a hole with asymmetrical shape. Thus, it is desirable to machine the workpiece without flushing. Additionally, if the conditions of low supply voltage, long pulse interval and low-density electrolyte are avairable for ECM, accurate machining may be possible. The properties of HVPA-ECM are examined. Fig. 8 shows the top views and cross-sectional shapes of the holes obtained by the conventional low-voltage pulsed ECM and HVPA-ECM. A $0.3 \mathrm{~mm} \phi$ rigid tool electrode is used instead of a pipe electrode. The electrolyte is weakly poured to the working gap from the side of the electrode. The low and high voltage pulses are a-synchronously supplied. The voltage of the high-voltage pulse is $100 \mathrm{~V}$, the pulse duration is 6 $\mu \mathrm{s}$, the pulse period is $1 \mathrm{~ms}$ and the restricting resistance of the high-voltage power supply is $3.2 \Omega$. In the case of the conventional low-voltage pulsed ECM, it is difficult to machine a hole. However, in the case of HVPA-ECM, it is possible to machine a hole in the workpiece. The asymmetry of the hole entrance shape is negligible. A large amount of bubbles caused by the high-density current might flush out the sludge from the working gap. The following results in the case of HVPA-ECM are obtained using a rigid electrode without jet flushing.

\subsection{Machining speed and hole shape}

Fig.9 shows the cross-sectional shapes of the holes
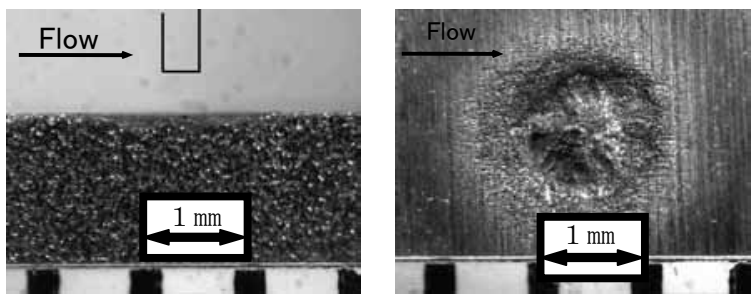

a) Without high voltage pulse
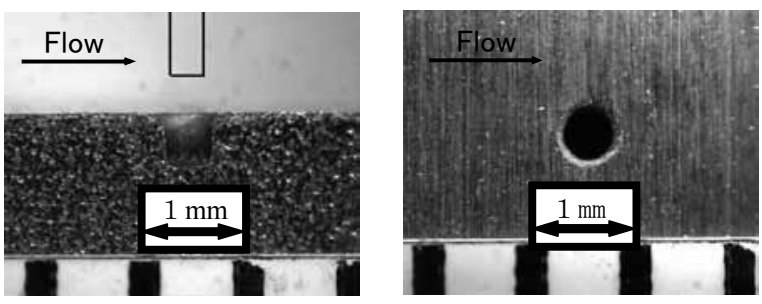

b) High voltage pulse assisted

Fig.8 Machined hole without jet flushing $\left(\mathrm{NaNO}_{3}: 0.5 \%, \mathrm{~V}_{\mathrm{L}}=15 \mathrm{~V}, \mathrm{t}_{\text {on }}{ }^{\mathrm{L}} / \mathrm{t}_{\text {off }} \mathrm{L}=10 / 10 \mu \mathrm{s}\right)$ obtained by HVPA-ECM compared with the results of the conventional ECM. The pulse duration of the low voltage is $10 \mu \mathrm{s}$, and the pulse interval is changed. The conditions of the high-voltage pulse are the same as those shown in Fig.8. Fig.10 shows the machining speeds and the side gap widths. The

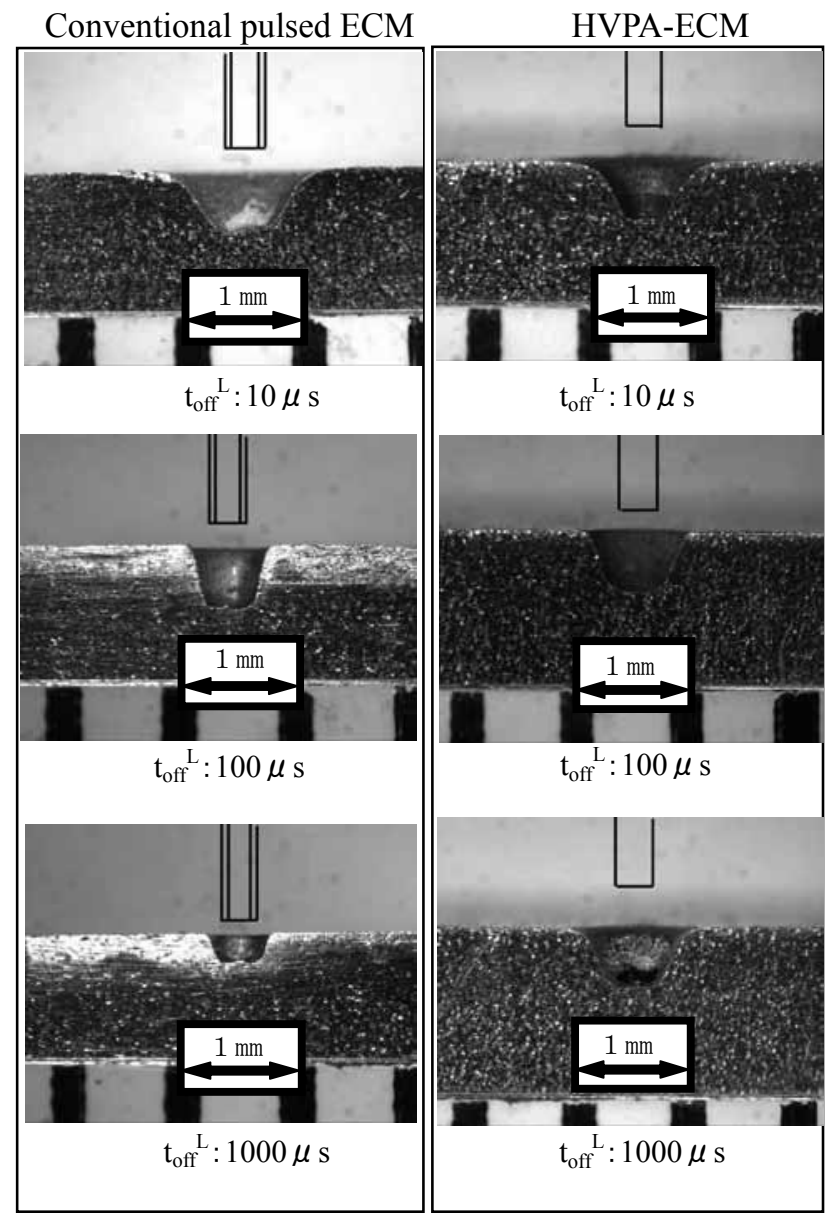

Fig.9 Influence of high voltage pulse

$\left(\mathrm{NaNO}_{3}: 5 \%, \mathrm{~V}_{\mathrm{L}}: 15 \mathrm{~V}, \mathrm{t}_{\text {on }}{ }^{\mathrm{L}}: 10 \mu \mathrm{s}, \mathrm{V}_{\mathrm{H}}: 100 \mathrm{~V}, \mathrm{t}_{\text {on }}{ }^{\mathrm{H}}: 6 \mu \mathrm{s}, \mathrm{T}_{\mathrm{H}}: 1 \mathrm{~ms}\right)$

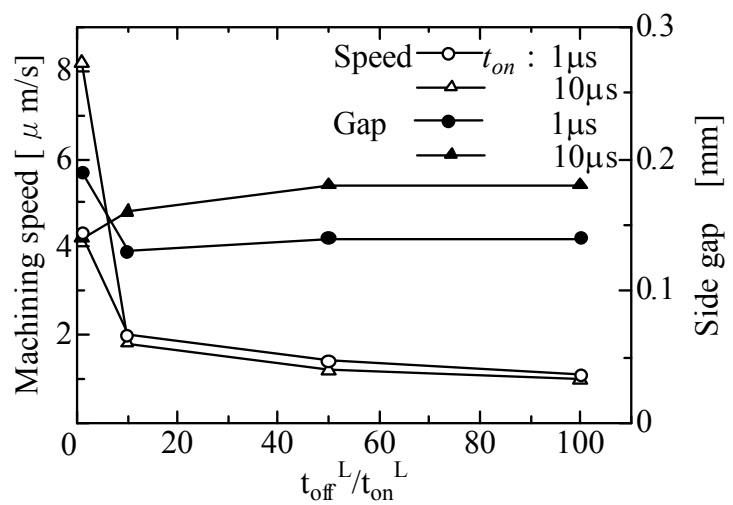

Fig.10 Influence of high voltage pulse on machining speed and side gap width

$\left(\mathrm{NaNO}_{3}: 5 \%, V_{L}: 15 \mathrm{~V}, \mathrm{~V}_{\mathrm{H}}: 100 \mathrm{~V}, \mathrm{t}_{\text {on }}{ }^{\mathrm{H}}: 6 \mu \mathrm{s}, \mathrm{T}_{\mathrm{H}}: 1 \mathrm{~ms}\right)$ 
machining speed is 3.5-6 times that of the conventional ECM in Fig.4, particularly in the case of a short pulse interval. The side gap width improves at the short pulse interval, but slightly deteriorates at the long pulse interval.The improvement of the side gap width at the short pulse interval may be caused by the increase in machining speed and the reduction in machining time.

\subsection{Effect of voltage of low-voltage pulse}

Fig.11 shows the effect of the voltage of the low voltage pulse on the machining speed and the side gap width in the case of HVPA-ECM. The electrolyte concentration is $0.5 \%$. The machining using a voltage of $5 \mathrm{~V}$ is possible; it was impossible by the conventional ECM. The side gap width is smaller than the results shown in Fig. 10 because of the usage of the low-density electrolyte. The low voltage causes the low machining speed. However, the side gap width is not improved by the low voltage.

\subsection{Effect of high-voltage pulse}

To determine the reason for the increase in

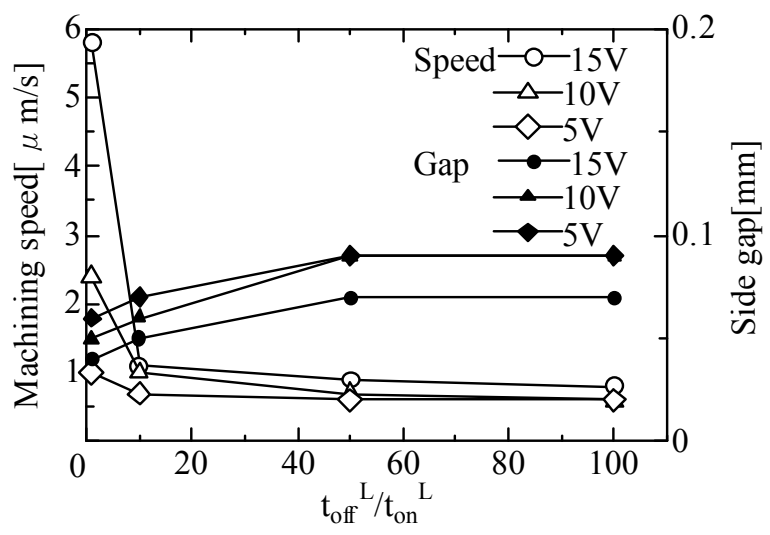

Fig.11 Influence of voltage of low voltage pulse $\left(\mathrm{NaNO}_{3}: 0.5 \%, \mathrm{t}_{\mathrm{on}}{ }^{\mathrm{L}}: 10 \mu \mathrm{s}, \mathrm{V}_{\mathrm{H}}: 100 \mathrm{~V}, \mathrm{t}_{\mathrm{on}}{ }^{\mathrm{H}}: 6 \mu \mathrm{s}, \mathrm{T}_{\mathrm{H}}: 1 \mathrm{~ms}\right)$

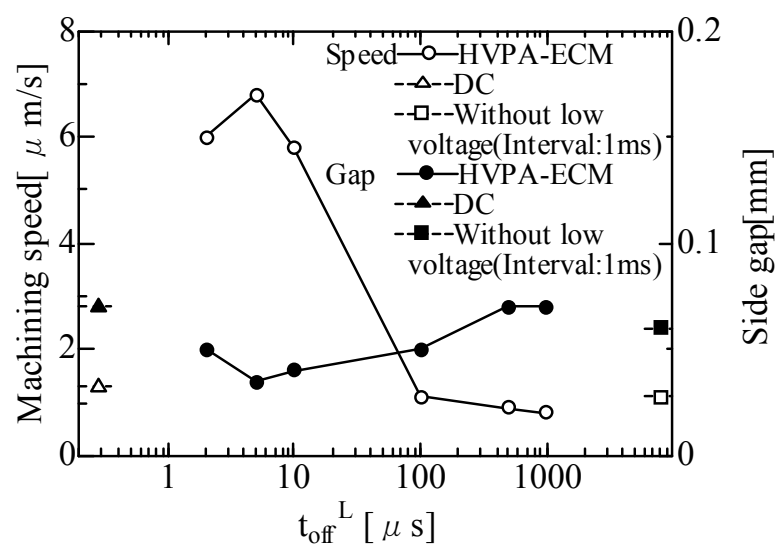

Fig.12 Influence of high voltage pulse

$\left(\mathrm{NaNO}_{3}: 0.5 \%, \mathrm{~V}_{\mathrm{L}}: 15 \mathrm{~V}, \mathrm{t}_{\mathrm{on}}{ }^{\mathrm{L}}: 10 \mu \mathrm{s}, \mathrm{V}_{\mathrm{H}}: 100 \mathrm{~V}, \mathrm{t}_{\mathrm{on}}{ }^{\mathrm{H}}: 6 \mu \mathrm{s}, \mathrm{T}_{\mathrm{H}}: 1 \mathrm{~ms}\right)$ machining speed by the usage of the high-voltage pulse, ECM with a high voltage pulse was performed, and the obtained results are compared with those of HVPA-ECM. Right-side data in Fig. 12 are the ECM results obtained using the high voltage pulse, but not using the low-voltage pulse. Left-side data are the ECM results obtained using the DC current without the high-voltage pulse and using a pipe electrode, for reference. The machining speed obtained using the high-voltage pulse without the low-voltage pulse is almost $1 / 6$ of the maximum speed obtained by HVPA-ECM. This means that the workpiece is mainly worked by the low-voltage pulsed current in HVPA-ECM, and that the high-voltage pulse assists the machining to remove the sludge in the working gap, which prohibits the machining and is produced by ECM.

\subsection{Discharge problem}

The discharge caused by the high-voltage pulse induces the wear of electrodes and weakens the merit of ECM. Fig.13 shows the effect of the duration of the high-voltage pulse on the cross-sectional shapes of the hole and the tool electrode. The discharge was checked by the spark and the sound. The long pulse causes the discharge and the wear of the tool electrode. The short pulse supresses the discharge and the wear of the tool electrode.

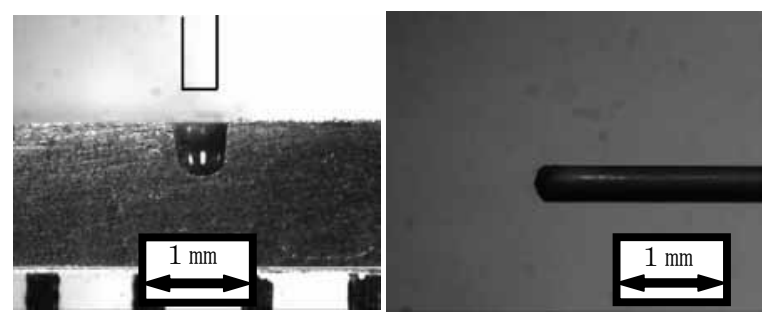

a) High voltage pulse $10 \mu \mathrm{s}$

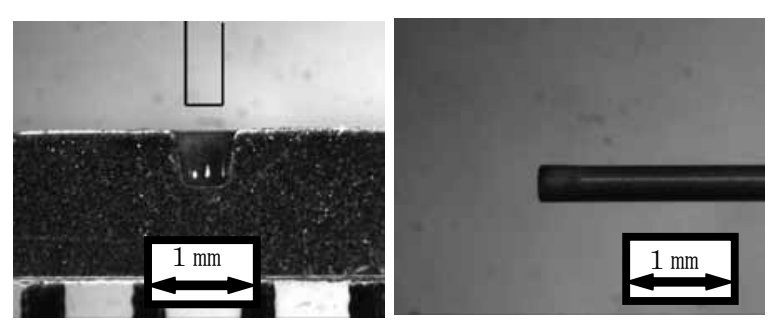

(b) High voltage pulse $4 \mu \mathrm{s}$

Fig.13 Shape of machined hole and electrode $\left(\mathrm{NaNO}_{3}: 0.5 \%, \mathrm{Vs}=15 \mathrm{~V}, \mathrm{t}_{\text {on }}{ }^{\mathrm{L}} / \mathrm{t}_{\text {off }}=10 / 10 \mu \mathrm{s}\right)$

\subsection{Influence of high-voltage pulse period}

Fig.14 shows the influence of the high-volatage pulse 
period. The long pulse period results in accurate machining, but makes the surface dull. The high voltage-pulse power makes the surface more brilliant.

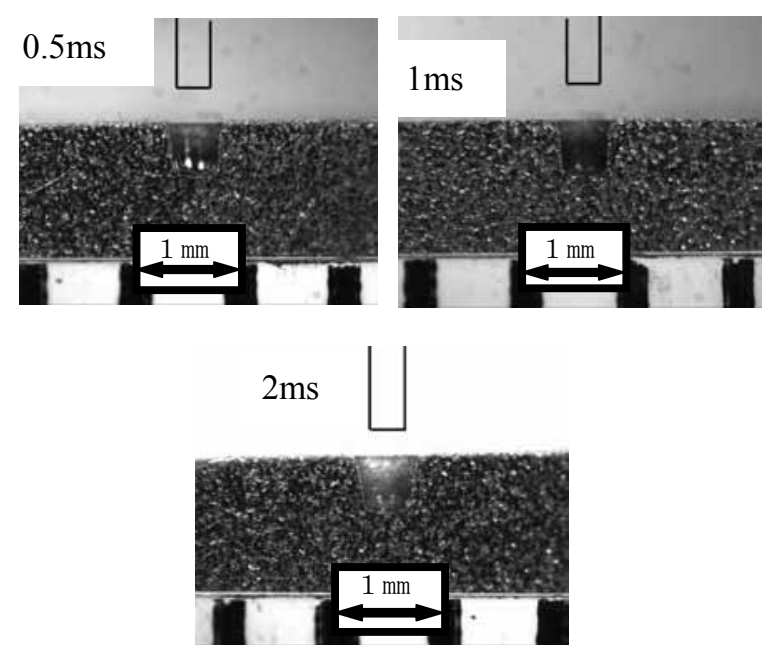

Fig.14 Influence of high voltage pulse period on shape of machined hole

$\left(\mathrm{NaNO}_{3}: 0.5 \%, \mathrm{~V}_{\mathrm{L}}=15 \mathrm{~V}, \mathrm{t}_{\text {on }}{ }^{\mathrm{L}} / \mathrm{t}_{\text {off }} \stackrel{\mathrm{L}}{\mathrm{L}}=10 / 10 \mu \mathrm{s}, \mathrm{V}_{\mathrm{H}}=100 \mathrm{~V}, \mathrm{t}_{\text {on }}{ }^{\mathrm{H}}=6 \mu \mathrm{s}\right)$

\subsection{Influence of electrolyte concentration}

Fig. 15 shows the cross-sectional shapes of the holes machined using the $0.5 \%$ and $0.05 \%$ electrolytes. It was possible to machine the workpiece with these low-density electrolytes. Additionally, the machining at the long pulse interval of $1000 \mu \mathrm{s}$ was possible. Fig. 16 shows the machining speeds and the side gap widths. The low electrolyte concentration causes the low machining speed and the small side gap width. The minimum side gap width of $20 \mu \mathrm{m}$ was obtained in the case of the $0.05 \%$ electrolyte. This value is comparable to the value obtained by

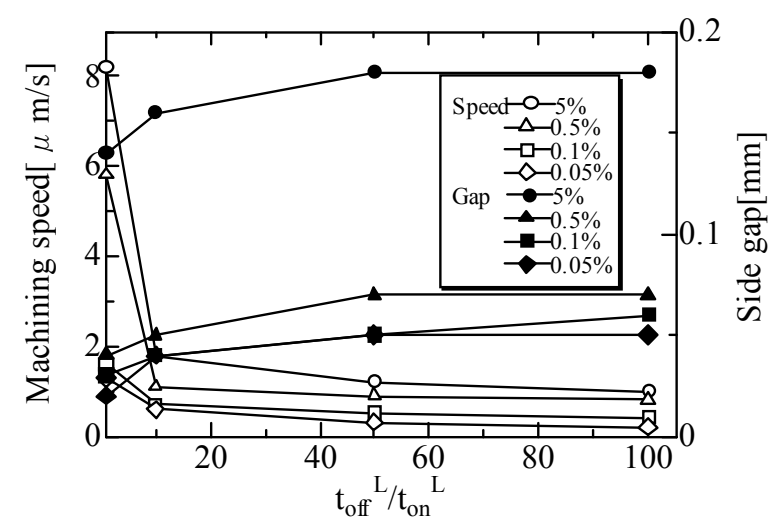

Fig.16 Influence of concentration of $\mathrm{NaNO}_{3}$ on machining speed and side gap width

$\left(\mathrm{NaNO}_{3}: 0.5 \%, \mathrm{~V}_{\mathrm{L}}: 15 \mathrm{~V}, \mathrm{t}_{\mathrm{on}}{ }^{\mathrm{L}}: 1 \mu \mathrm{s}, \mathrm{V}_{\mathrm{H}}: 100 \mathrm{~V}, \mathrm{t}_{\mathrm{on}}: 6 \mu \mathrm{s}, \mathrm{T}_{\mathrm{H}}: 1 \mathrm{~ms}\right)$

EDM. The high-voltage pulse makes it possible to use the conditions that are difficult to use in the conventional ECM, and it makes it possible to improve the accuracy of ECM.

\section{DISCUSSION}

The above results show that the additional supply of a high-voltage pulse in the ECM makes machining possible in a wide range of ECM conditions, which is impossible in the conventional ECM. Consequently, it makes machining in a stagnant electrolyte possible, increasing the machining speed and decreasing the side gap width. It is well known that the current density over the value of $20 \mathrm{~A} / \mathrm{cm}^{2}$ in ECM increases the efficiency of the current and the glossiness of the surface. The high-voltage pulse may remove the passive layer from the ECMed surface. However, there are possibilities that the high-voltage pulse

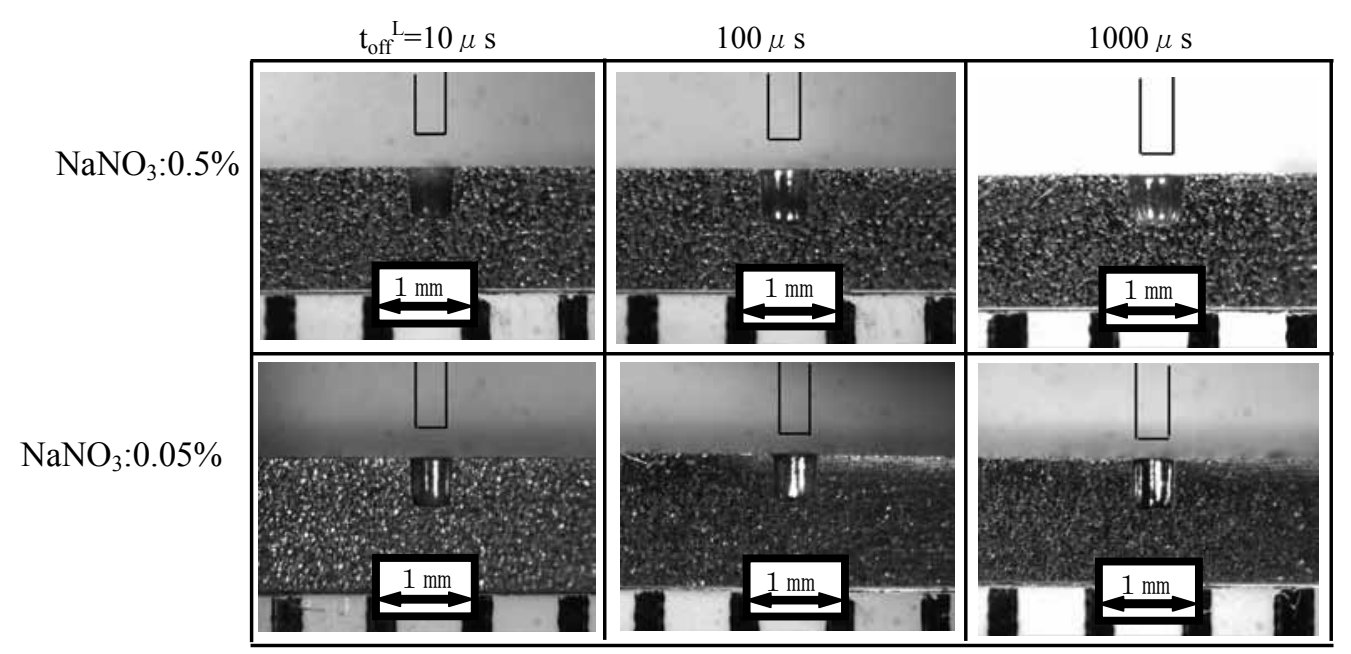

Fig.15 Influence of concentration of $\mathrm{NaNO}_{3}$ on shape of machined hole

$$
\left(\mathrm{V}_{\mathrm{L}}: 15 \mathrm{~V}, \mathrm{t}_{\mathrm{on}}{ }^{\mathrm{L}}: 10 \mu \mathrm{s}, \mathrm{V}_{\mathrm{H}}: 100 \mathrm{~V}, \mathrm{t}_{\mathrm{on}}{ }^{\mathrm{H}}: 6 \mu \mathrm{s}, \mathrm{T}_{\mathrm{H}}: 1 \mathrm{~ms}\right)
$$


causes a hole overcut. In our HVPA-ECM examination, the current density of the high-voltage pulse was $200-300 \mathrm{~A} / \mathrm{cm}^{2}$, but no large hole overcut was observed. This is because of the low duty ratio of the high-voltage pulse, which is sufficient for removing the passive layer from the ECMed surface, but not sufficient for machining the workpiece.

The mechanism of passive layer removal is not clear. One possible mechanism is the generation of a large amount of gas bubbles on the surface of the workpiece caused by the high current that may destroy the passive layer. However, Chikamori et al. ${ }^{6}$ ) reported that the amount of $\mathrm{H}_{2}$ gas on the tool electrode increases with the current density; reversely, the gas generated on the workpiece is $\mathrm{O}_{2}$, whose amount decreases with the current density. Hence, it is difficult to expect the generation of $\mathrm{O}_{2}$ gas for the removal of the passive layer. On the other hand, Mao et al. ${ }^{7)}$ described that the $\mathrm{H}^{+}$ion produced by the generation of $\mathrm{O}_{2}$ gas decreases $\mathrm{PH}$ on the workpiece and dissolves the passive layer, which may be reasonable. The mechanism that involves a very high current density should be investigated well.

The usage of high-voltage pulses makes it possible to machine workpieces without strong flushing. This is due to the destruction of the passive layer by the high density current and the generation of the large amount of $\mathrm{H}_{2}$ gas that remove the sludge. This flushing out mechanism may be effective for small electrodes, but not enough for large electrodes. For large electrodes, there should be other flushing out mechanisms involved, such as the electrode jump used by Sakai et al. ${ }^{3)}$.

For the practical use of ECM for sinking, there are other problems to be solved. One problem is the discharge between electrodes. The transcript of the discharged crater of the tool electrode on the surface of the workpiece should be avoided. The usage of the short high voltage pulse is effective in preventing the discharge, but is not the most efficient method. A more effective method of preventing the discharge is required for the practical use of ECM.

\section{CONCLUSIONS}

The conventional ECM has some problems. It requires holes in electrodes for strong flushing in the gap, and it is difficult to use wide-range ECM conditions for accurate machining. A newly developed high-voltage pulse-assisted ECM is proven effective in solving these problems and has the following features;

(1) It is possible to machine workpieces without strong flushing in the case of small electrodes. It does not require holes in small electrodes for flushing.

(2) It is possible to machine workpieces using lowdensity electrolytes, long pulse intervals and lowvoltage pulses.

(3) The high-voltage pulse increases the machining speed from 3 to 6 times and decreases the side gap width in the short-pulse interval region. In particular, by using a very low density electrolyte, a side gap width that is comparable to the gap width obtained by EDM is achieved.

(4) The shortening of the high voltage pulse is effective in preventing the discharge between electrodes.

\section{REFERENCES}

1) R. Shuster, V. Kirchner, P. Allongue, G. Ertl, Electrochemical Micromachining, Science 289 (2000), 98-101

2) K. Chikamori, S. Ito, Electrochemical Machining in Stagnant Electrolyte, J. of the Japan Society of Electrical Machining Engineers, Vol.9, No.18 (1976), 19-28

3) S. Sakai, T. Masuzawa, S. Ito, ECM Finishing of Surface Products by EDM, ISEM9, (1989), 155-158

4) A. K. M. De Silva, H. S. J. Altena, J. A. McGeough, Precision ECM by Process Characteristic Modeling, Annals of the CIRP, Vol.49/1 (2000), 151-155

5) A. K. M. De Silva, H. S. J. Altena, J. A. McGeough, Influence of Electrolyte Concentration on Copying Accuracy of Precision ECM, Annals of the CIRP, Vol.52/1 (2003), 165-168

6) K. Chikamori, H. Yamamoto, S. Ito, A Stoichiometic Investigation of ECM, J. of the Japan Society of Electrical Machining Engineers, Vol.8, No.16(1975), 10-18

7) Kao-Wen Mao, M. A. LaBoda, J. P. Hoare, Anodic Film Studies on Steel in Nitrate-based Electrolytes for Electrochemical Machining, J. Electrochem. Soc., Vol. 119 (1972), 419. 